\title{
Gravitational depletion of the early Earth's upper mantle and the viability of early plate tectonics
}

\author{
Geoffrey F. Davies * \\ Research School of Earth Science, Australian National University, Canberra, ACT 0200, Australia \\ Received 1 November 2005; received in revised form 24 January 2006; accepted 26 January 2006 \\ Available online 3 March 2006 \\ Editor: S. King
}

\begin{abstract}
Numerical modelling of stirring of subducted mafic (oceanic) crust in the hot early mantle yields an upper mantle strongly depleted of mafic components due to gravitational settling, while the lower mantle becomes marginally enriched, with a thin dense layer at the base. These results accord with the very early and strong depletion of incompatible trace elements in the mantle source of the oldest rocks. They support a recent geochemical argument that the depletion is due more to the extraction of mafic material rather than of continental crust. The strong depletion would yield a thin oceanic crust, despite the high temperature of the mantle, which would make early plate tectonics more viable.
\end{abstract}

(C) 2006 Elsevier B.V. All rights reserved.

Keywords: early mantle; trace-element depletion; plate tectonics; mantle convection

\section{Introduction}

No rocks and only some zircon crystals are known to have survived from the Earth's Hadean era (4.5-4 Ga ago), while only limited regions of continental crust survive from the earlier part of the Archean era (4-2.5 Ga) [1-3]. Even so some important observations are available pertaining to those times, though not surprisingly there are still basic questions about how the Earth was behaving.

For example, it is not clear whether plate tectonics was operating in something like its modern form. Also, although the early mantle was strongly depleted of the incompatible trace elements that tend to accumulate in

\footnotetext{
* Tel.: +61 261254517.

E-mail address: Geoff.Davies@anu.edu.au.
}

continental crust, prevailing opinion has been that little continental-type crust existed in the Hadean. A third question is whether there was any compositional or dynamical layering in the early mantle. Such layering is debated even for the present mantle, and past or present layering might help to explain the persistence in the convecting mantle of heterogeneities in trace elements and isotopes that appear to be up to $2 \mathrm{Ga}$ old.

The tectonic plates comprise the cool thermal boundary layer that drives a "plate mode" of mantle convection [4]. If the mantle was hotter in the past, there would have been more melting under mid-ocean ridges, yielding a thicker oceanic crust. However, as the oceanic crust is less dense than the mantle, it tends to inhibit the subduction of oceanic plates and thus reduces the forces driving plate tectonics [5]. By conventional estimates, the Archean mantle would 
have been hot enough to yield $30-\mathrm{km}$-thick oceanic crust. In order to subduct, a plate would have to age until its negative thermal buoyancy overcame the positive compositional buoyancy of the oceanic crust, and thus plate tectonics would have been substantially slowed. Plates could still have operated, but they might not have kept the mantle from overheating from its internal radioactivity [5]. However oceanic crust converts to a denser mineral assemblage at depths of $60 \mathrm{~km}$ or more, which may have permitted subduction to continue if it could once be started. This might have resulted in plates operating episodically [5].

Geological evidence is equivocal as to whether or not plate tectonics operated, as there are both similarities and differences between ancient tectonic patterns and rock types and their modern counterparts generated by plate tectonics [3].

Regarding the second question noted above, the present mantle source of mid-ocean ridge basalts is depleted of incompatible elements, which is commonly attributed to it being the residue left from the extraction of the continental crust $[6,7]$. However the early mantle was even more strongly depleted [8-10]. Two ideas have competed to explain this. A minority has argued for a substantial amount of early continental crust which was subsequently recycled into the mantle, leaving little trace $[11,12]$. Others have proposed an early reservoir of mafic material. This reservoir might have existed as a thick crust at the Earth's surface [13], or it might have foundered to the base of the mantle $[14,15]$.

As well there is accumulating geochemical evidence that the silicate part of the Earth (the crust and mantle) that is accessible to direct and indirect sampling is, on average, slightly depleted relative to presumed chondritic meteorite precursors $[15,16]$. This suggests a hidden enriched reservoir, although it remains possible that chondritic meteorites are not representative of the Earth. Blichert-Toft and Albarède [15] argue that foundered ancient mafic material is more plausible geochemically than a near-surface crustal reservoir.

On the other hand, the existence of ancient zircons dating from the Hadean era indicates the presence of at least some sialic (continental-type) crust at that time [1], and oxygen isotope and other geochemical signatures indicate the presence of water $[10,17,18]$. Also hafnium isotopes from a significant proportion of Hadean zircons reflect mantle source depletion, which suggests substantial volumes of mantle had been depleted [10]. Thus a picture of the Hadean Earth being not so different from the present, with a cool surface, oceans and large continental masses, has been advocated [10].
Campbell [19] has developed a third geochemical line of evidence, using the diagnostic ratios $\mathrm{Nb} / \mathrm{U}, \mathrm{Th} / \mathrm{U}$ and $\mathrm{Sm} / \mathrm{Nd}$ that distinguishes between the signatures of sialic versus mafic extraction in the residual mantle source material. His results indicate that by the late Archean the depletion was variable in kind but due more to mafic than to sialic extraction.

Regarding the question of mantle layering, there is strong seismological evidence for a compositionally distinct zone in the lowest $200-300 \mathrm{~km}$ of the present mantle, the so-called $\mathrm{D}^{\prime \prime}$ region [20], and there are some who argue for a less distinct interface in the range 1500$2000 \mathrm{~km}$ depth [21]. Even if no mid-mantle interface exists at present, such an interface might have existed in the past, though this is difficult to test.

Two ideas have been proposed to explain the $\mathrm{D}^{\prime \prime}$ region. Hofmann and White [22] suggested that subducted oceanic crust, which is expected to be denser than average mantle through most of the depth of the mantle, would settle into the $\mathrm{D}^{\prime \prime}$ region (some of it later to be returned to the Earth's surface by mantle plumes). On the other hand Tolstikhin and Hofmann [23] propose that $\mathrm{D}^{\prime \prime}$ comprises or includes material preserved from the Earth's formation. A lot of geochemical evidence has accumulated to support the first idea [7], though the two possibilities are not mutually exclusive.

Here numerical modelling results are presented that illuminate all of these questions. Numerical models have previously been used to explore the Hofmann and White hypothesis by modelling the behaviour of denser, subducted mafic material in a convecting mantle $[24,25]$, though the models were run at present mantle conditions of temperature and viscosity. The present models explore the processes in a hotter early mantle in which the viscosity is lower.

Christensen and Hofmann [24] found that some subducted mafic material formed "pools" under mantle upwellings, although much of it still remained in suspension in the mantle. Davies [25] extended the Christensen and Hofmann models to somewhat more realistic conditions, and in particular included a viscosity contrast between the upper and lower mantles, as there is independent evidence that the lower mantle is about 30 times more viscous than the upper mantle [26], probably due to pressure-induced phase transformations in the transition zone of the mantle. Davies confirmed the occurrence of mafic pools, but also found some segregation of heavy and light components within the upper mantle, due to its lower viscosity. The latter segregation produced a vertical gradient of basaltic concentration through the upper mantle, with the uppermost mantle being depleted by $20-30 \%$. 

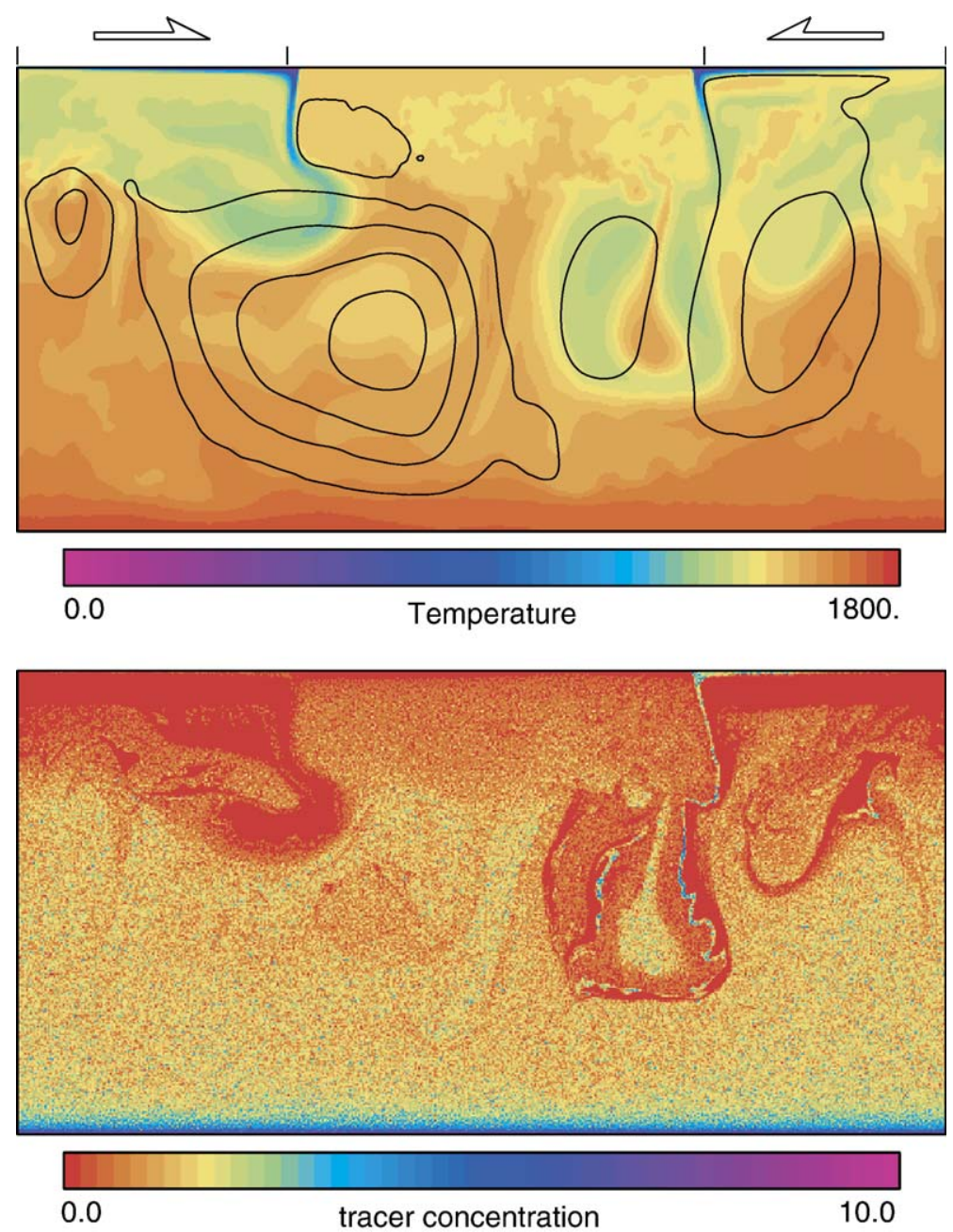

Fig. 1. Temperature and streamlines (upper) and tracer concentration (lower) after $500 \mathrm{Ma}$ of subduction and convective stirring in the mantle. The model features two "oceanic" plates converging towards and subducting under a central "continental" region. The tracers represent the mafic component of the mantle composition, and simulate both its melting near the surface and its excess density in the mantle (see text). Melting concentrates the tracers into an oceanic "crust", and because of their greater density they settle out of the lower viscosity upper mantle (the upper $30 \%$ of the model), leaving it relatively depleted. Some tracers also accumulate at the base of the model, although many remain suspended in the lower mantle, which is 30 times more viscous than the upper mantle. See Davies [25] for more model details.

The Christensen-Hofmann and Davies models were run with constant mantle temperatures, since the higher temperatures of the early mantle were technically challenging at the time because of the larger viscosity contrasts that would occur. Davies took indirect account of the higher temperature of the mantle in the past by running the models for $18 \mathrm{Ga}$, this being the time required, at present rates, for mantle convection to achieve the total number of overturns estimated to have occurred since about 4.5 Ga ago. However hotter models have still been required because an important effect of higher mantle temperature is to reduce its viscosity, which might enhance segregation of the mafic components. Models by Ogawa [27] tend to confirm this expectation, though he did not characterise this aspect systematically.

Approximate "parameterised" calculations of thermal evolution indicate that the mantle has cooled by perhaps $200-300{ }^{\circ} \mathrm{C}$ since about $4 \mathrm{Ga}$ ago due to the slow decline of radioactive heat production [28]. Here models have been run at a temperature $250{ }^{\circ} \mathrm{C}$ higher than the present mantle, which corresponds to about 4.2 $\mathrm{Ga}$ ago according to conventional thermal histories. At this stage only two-dimensional models are feasible for a hot mantle because of the very high resolution required to resolve the thin boundary layers. (Threedimensional models are only just becoming feasible for present mantle conditions.) 


\section{Numerical modelling}

The model setup is similar to that used by Davies [25]. The model (Fig. 1) is two-dimensional, in a $2 \times 1$ box, with simulated plates on the top boundary and an insulating, free-slip bottom boundary. (The use of plates on the top boundary is not clearly justified, as already discussed, but they are used here to facilitate comparison with models under present mantle conditions.) The end walls of the model are periodic, mimicking the closure of the mantle around the core.

The lower, insulating boundary of the model excludes the formation of plumes. This choice is made because plumes cannot be well modelled in two dimensions and in any case they may have been secondary throughout Earth history [28]. The exclusion of bottom heating reduces the stirring of sedimented tracers back into the flow, but tests, to be reported elsewhere, indicate the effect is secondary.

The reference (upper mantle) temperature of the model is $1550{ }^{\circ} \mathrm{C}$, compared with a nominal $1300^{\circ} \mathrm{C}$ for the present mantle. Internal radioactive heat production is equivalent to a surface heat flux of $180 \mathrm{~mW} / \mathrm{m}^{2}$, compared with $35.5 \mathrm{~mW} / \mathrm{m}^{2}$ in the models of the present mantle.

Plates are simulated by imposing piecewise-constant horizontal velocities on the top boundary. In combination with the temperature-dependent viscosity (see below) this results in plate-like behaviour both before and after subduction. Whereas the "oceanic" plates have zero temperature at the surface, the central "continental" region of the top boundary is insulating and therefore takes on the interior temperature, thus simulating the base of a slow-moving continent. The locations of the subduction zones oscillate slowly through a small distance range. See Davies [25] for more detail. Plate velocities are scaled by the average upper mantle temperature and viscosity, via the temperature-based Rayleigh number to the power $2 / 3$, being about $300 \mathrm{~mm} / \mathrm{yr}$, compared with $50 \mathrm{~mm} / \mathrm{yr}$ at present. With this velocity, the plates are only 10-15 Ma old at subduction.

The viscosity in the model depends on both temperature and depth. A strong temperature dependence, with an activation energy of $390 \mathrm{~kJ} / \mathrm{mol}$, is included, although the maximum viscosity variation due to temperature is capped at 100 times the upper mantle viscosity. Because of the higher temperature, all viscosities are about a factor of 60 lower than for the present mantle - the reference upper mantle viscosity at $1550{ }^{\circ} \mathrm{C}$ is $4.9 \times 10^{18} \mathrm{~Pa} \mathrm{~s}$, compared with $3 \times 10^{20}$ at $1300{ }^{\circ} \mathrm{C}$. Depth-dependence is then imposed by multiplying the viscosity by a smoothed step function, increasing by a factor of 30 at a depth of about $800 \mathrm{~km}$.

With a dimensional box depth of $3000 \mathrm{~km}$, these conditions yield a Rayleigh number based on heat flux [4] of $7.7 \times 10^{11}$. The computational grid is uniform and $256 \times 512$, so the dimensional cell size is $11.7 \mathrm{~km}$.

Mafic material is represented in the model by tracers. There are 500,000 tracers with an initial average spacing of $6 \mathrm{~km}$. Tests with more tracers indicate the results are accurate within uncertainties of the model parameters. As fluid rises through the depth of the solidus, melting is simulated by removing tracers and placing them in a thin crustal layer. This leaves a layer of fluid depleted of tracers, simulating the depleted residue of the oceanic crust source. The melting depth in the models is estimated from the mean upper mantle temperature and the eclogite solidus versus depth [29]. The variation of crustal thickness with temperature is taken from McKenzie and Bickle's estimates for modern, moderately depleted mantle, calibrated to yield $7 \mathrm{~km}$ at $1300{ }^{\circ} \mathrm{C}$ [30]. The latter method of estimation is not fully consistent with the eclogite melting implied by the melting model, but it is assumed to be useful in this initial exploration. Eclogite melting is used because mantle melting, and the consequent production and foundering of basalt, is likely to have proceeded rapidly during and after Earth's accretion, so the mantle's basaltic component is likely to have existed as eclogite in the

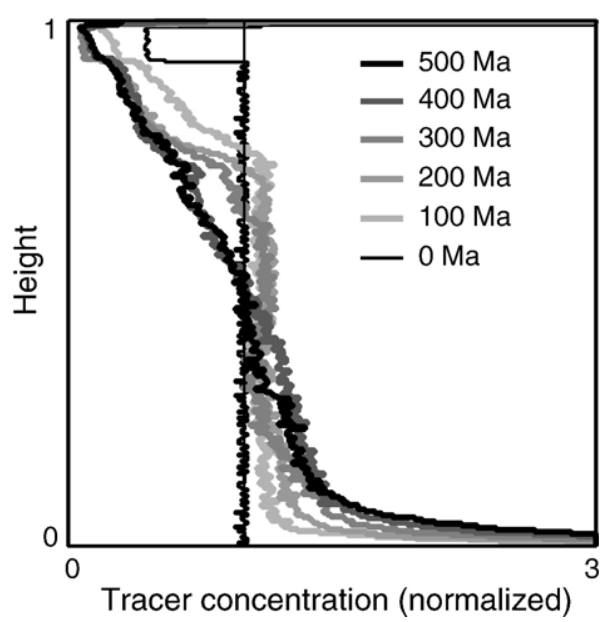

Fig. 2. Vertical profiles of horizontally averaged tracer concentration at various times in the model shown in Fig. 1. Tracer concentration is normalised to the average concentration in the model, revealing a rapid depletion of the upper mantle, a slight enrichment of the lower mantle and a strongly enriched thin layer at the base. The concentration in the basal layer reaches (and is limited to) about 10, corresponding to pure mafic material. 
upper mantle, rather than as a homogeneously fertile mantle (the same is likely to be true of the modern mantle). With these approximations, at $1550{ }^{\circ} \mathrm{C}$ melting extends to $228 \mathrm{~km}$ depth, the average melt fraction of undepleted mantle would be $12.3 \%$ and the crustal thickness would be $28 \mathrm{~km}$.

Subduction returns the crustal layer and the depleted layer to the mantle, where they are stirred by mantle convection. These and other features of the model are described in more detail by Davies [25]. The simulated melting is suppressed under the "continental" region in the center, since the upper boundary there is taken to be the base of continental lithosphere at around $200 \mathrm{~km}$ depth, under which little melting should occur.

The tracers each carry a small mass anomaly, corresponding to the higher density of the mafic component at depth, in its eclogite form, relative to average mantle. Excess densities in the upper mantle range between $100 \mathrm{~kg} / \mathrm{m}^{3}$ and $200 \mathrm{~kg} / \mathrm{m}^{3}$ but mainly between $100 \mathrm{~kg} / \mathrm{m}^{3}$ and $150 \mathrm{~kg} / \mathrm{m}^{3}$ [31,32], though it may be smaller in the lower mantle. A reference value of $150 \mathrm{~kg} / \mathrm{m}^{3}$ is used here.

\section{Results}

Fig. 1 shows distributions of temperature, flow and tracers after $500 \mathrm{Ma}$ of model evolution. The upper mantle is cooler and more depleted of tracers than most of the lower mantle, except where recently subducted cooler fluid penetrates the lower mantle. A thin, concentrated layer of tracers has formed at the bottom. The rest of the fluid has divided approximately into two kinds, a cooler, depleted fluid above and a warmer, slightly enriched fluid below. The thermal and compositional buoyancies trade off so the net densities are not very different.

The depletion of the upper mantle is due to gravitational separation of the denser subducted oceanic crust from the lighter depleted fluid, and is facilitated by the lower viscosity of the upper mantle. The separation evidently does not occur immediately upon subduction, as can be verified under the right-hand subduction zone in Fig. 1, but later as crustal material slowly settles through the upper mantle. The viscosity of the lower mantle is evidently still high enough to keep many tracers in suspension. The development through time of
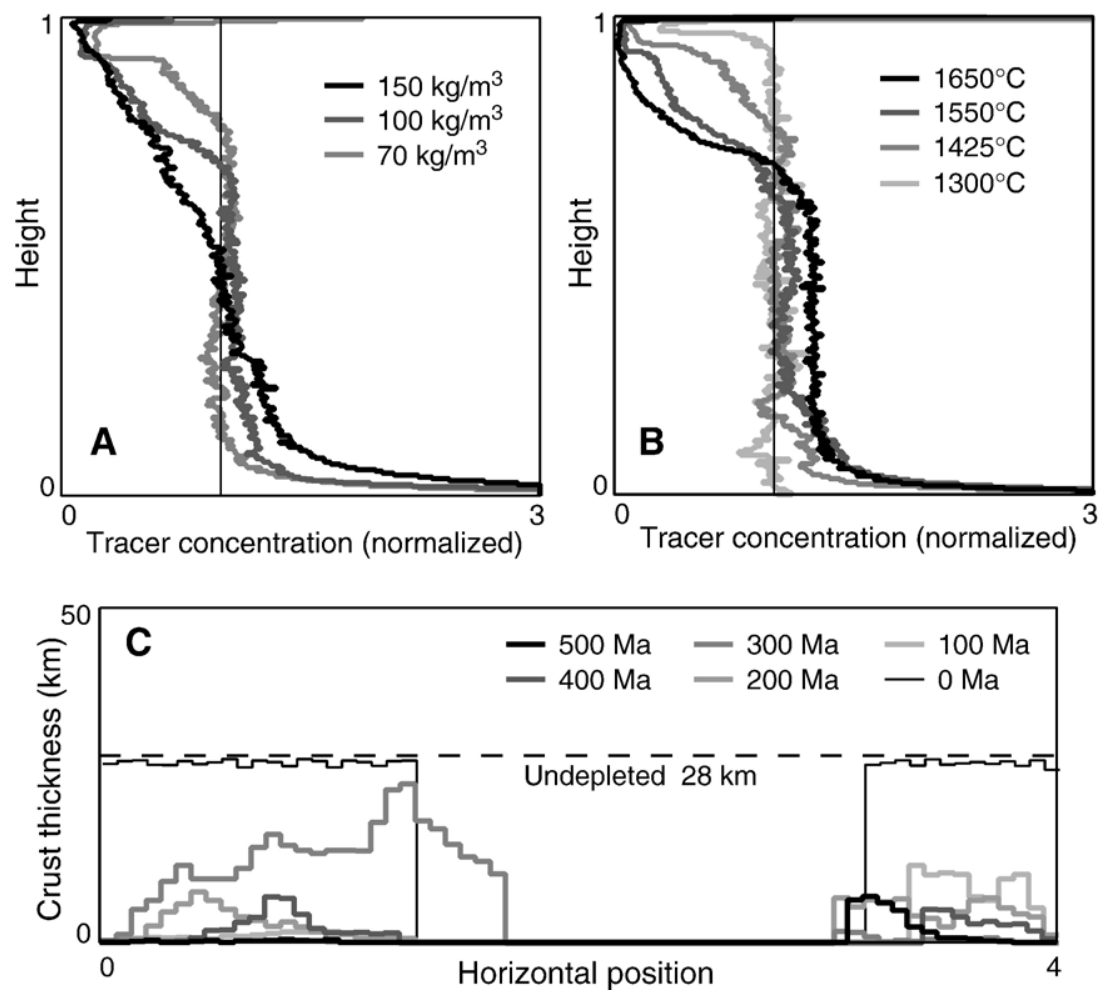

Fig. 3. (A) Tracer profiles for different excess densities of subducted oceanic crust. (B) Tracer profiles at different mantle temperatures. Models are compared after comparable numbers of overturns (after $100 \mathrm{Ma}, 300 \mathrm{Ma}, 800 \mathrm{Ma}$ and $4000 \mathrm{Ma}$, in order of decreasing temperature). (C) Nominal crustal thickness at various times from the model shown in Fig. 1. Undepleted mantle would yield a thickness of $28 \mathrm{~km}$. 
the stratification is illustrated in Fig. 2. The upper mantle depletion occurs within $200 \mathrm{Ma}$ and a complementary enrichment of the lower mantle can be seen. Subsequently, depleted material intrudes increasingly into the lower mantle, as is also evident in Fig. 1. The thin, dense layer at the base develops mainly within the first 300 $\mathrm{Ma}$, although some slow accumulation is still occurring at $500 \mathrm{Ma}$.

The robustness of this behaviour has been tested in models with different parameters. The tracer concentration profiles in Fig. 3A show that upper mantle depletion is weaker at $70 \mathrm{~kg} / \mathrm{m}^{3}$ but substantial at $100 \mathrm{~kg} / \mathrm{m}^{3}$. In Fig. 3B tracer profiles are shown for various mantle temperatures after comparable amounts of overturning. Upper mantle depletion is strong at $1650^{\circ} \mathrm{C}$ and 1550 ${ }^{\circ} \mathrm{C}$, weaker at $1425{ }^{\circ} \mathrm{C}$ and minor at $1300{ }^{\circ} \mathrm{C}$. These differences result from a combination of the higher upper mantle viscosity at lower temperatures and the thinner depleted zone, which therefore has less local buoyancy.

A direct effect of the upper mantle depletion would be reduced melting under mid-ocean ridges and thus thinner oceanic crust. A notional crustal thickness has been calculated from the number of tracers in the model crust zone. This is a measure of the depletion of the material rising into the melting zone. The model thickness is quite variable (Fig. 3C), reflecting heterogeneity in the model, but averages only $4 \mathrm{~km}$, compared with $28 \mathrm{~km}$ for undepleted mantle. Excluding the burst of thicker crust at $300 \mathrm{Ma}$, the average is only $2.8 \mathrm{~km}$. Thus even material upwelling under spreading centers is depleted of $85-90 \%$ of its basaltic component.

\section{Discussion}

The strong depletion in mafic component of the upper mantle accords with the strong trace element depletions inferred from $\mathrm{Nd}$ and $\mathrm{Hf}$ isotopic ratios in the oldest rocks and zircons that were discussed earlier. This model provides a mechanism for the puzzling fact that the early depletion was stronger than the present depletion of the upper mantle.

The results also support Campbell's inference [19] that the early depletion was due mainly to the extraction of mafic material, rather than continental material. This in turn reduces the need to appeal to a massive early continental crust to explain the depletion, though it by no means excludes the possibility of a significant volume of early continental crust.

The enrichment of the lower mantle and the formation of a strongly enriched basal layer supports the plausibility of a "hidden" reservoir of material that has survived from earliest times, so that the bulk silicate Earth might be a little more enriched than usual estimates. It remains to be seen how much of the model stratification would survive until the present, since models at present conditions yield much less depletion of the upper mantle. The thin deep layer does form at present conditions [25], so it is likely also to survive from earlier times, and thus to be a least part of the explanation for the $\mathrm{D}^{\prime \prime}$ layer. The deep pools of mafic material play an important role in explaining the long apparent residence times of isotopic heterogeneities in the mantle [25].

The moderate enrichment of most of the lower mantle, if it survived to the present, might also be a plausible source of the FOZO (focal zone) component inferred from several isotopic systems [33]—FOZO is less depleted than the modern source of mid-ocean ridge basalts and seems to be fairly pervasive in the modern mantle. A more enriched lower mantle might also affect estimated total budgets of trace elements, and help to explain an apparent deficiency in radioactive heat generation in the mantle [4].

The much thinner oceanic crust estimated from these models would substantially improve the viability of subduction, and hence of plate tectonics, in the earliest Earth [5]. This would also help to resolve the paradox that plausible heat removal mechanisms have seemed to become less efficient at higher mantle temperatures, implying that too high an initial temperature could lead to a mantle thermal runaway [4].

The crust produced by melting such depleted mantle would be very mafic, possibly komatiitic. However no attempt has been made here to consider such details of composition or petrology, since this study is intended only to explore first-order effects. Similarly, potential differentiation at subduction zones that might result in the formation of continental crust has not been considered.

All of these results and inferences will need to be confirmed by more extensive searches of parameter space. Three-dimensional models will also be required, and such models with near-present mantle conditions, analogues of those of Davies [25], are currently being explored. The robustness of the present results will also need to be tested in evolving models that take account of declining radioactive heating and temperature with time.

\section{Acknowledgements}

This work was supported by Australian Research Council Grant DP0451266. Comments by Norm Sleep and an anonymous reviewer helped to improve the manuscript. 


\section{References}

[1] W. Compston, R.T. Pidgeon, Evidence of more very old zircons in Western Australia, Nature 321 (1986) 766-768.

[2] D.O. Froude, T.R. Ireland, P.D. Kinny, I.S. Williams, W. Compston, I.R. Williams, J.S. Myers, Ion microprobe identification of 4100 4200 Myr-old terrestrial zircons, Nature 304 (1983) 616-618.

[3] A.M. Goodwin, Principles of Precambrian Geology, Academic Press, New York, 1996.

[4] G.F. Davies, Dynamic Earth: Plates, Plumes and Mantle Convection, Cambridge University Press, Cambridge, 1999 460 pp.

[5] G.F. Davies, On the emergence of plate tectonics, Geology 20 (1992) 963-966.

[6] A.W. Hofmann, Chemical differentiation of the Earth: the relationship between mantle, continental crust, and oceanic crust, Earth Planet. Sci. Lett. 90 (1988) 297-314.

[7] A.W. Hofmann, Mantle chemistry: the message from oceanic volcanism, Nature 385 (1997) 219-229.

[8] V.C. Bennett, A.P. Nutman, M.T. McCulloch, Nd isotopic evidence for transient, highly depleted mantle reservoirs in the early history of the Earth, Earth Planet. Sci. Lett. 119 (1993) 299-317.

[9] F. Albarède, J. Blichert-Toft, J.D. Vervoort, J.D. Gleason, M. Rosing, Hf-Nd isotope evidence for a transient dynamic regime in the early terrestrial mantle, Nature 404 (2000) 488-490.

[10] T.M. Harrison, J. Blichert-Toft, W. Müller, F. Albarède, P. Holden, S.J. Mojzsis, Heterogeneous Hadean hafnium: evidence of continental crust at 4.4 to $4.5 \mathrm{Ga}$, Science 310 (2005) $1947-1950$.

[11] R.L. Armstrong, Radiogenic isotopes: the case for crustal recycling on a near steady-state no-continental-growth Earth, Philos. Trans. R. Soc. Lond. Ser. A 301 (1981) 443-472.

[12] E.B. Watson, T.M. Harrison, Zircon thermometer reveals minimum melting conditions on earliest Earth, Science 308 (2005) 841-844

[13] C.G. Chase, P.J. Patchett, Stored mafic/ultramafic crust and early Archean mantle depletion, Earth Planet. Sci. Lett. 91 (1988) 66-72.

[14] S.J.G. Galer, S.L. Goldstein, Early mantle differentiation and its thermal consequences, Geochim. Cosmochim. Acta 55 (1991) 227-239.

[15] J. Blichert-Toft, F. Albarede, The Lu-Hf isotope geochemistry of chondrites and the evolution of the mantle-crust system, Earth Planet. Sci. Lett. 148 (1997) 243-258 (Correction 154, 349).

[16] M. Boyet, R.W. Carlson, ${ }^{142} \mathrm{Nd}$ evidence for early $(>4.53 \mathrm{Ga})$ global differentiation of the silicate Earth, Science 309 (2005) $576-581$
[17] S.A. Wilde, J.W. Valley, W.H. Peck, C.M. Graham, Evidence from detrital zircons for the existence of continental crust and oceans on the Earth 4.4 Gyr ago, Nature 409 (2001) 175-178.

[18] S.J. Mojzsis, T.M. Harrison, R.T. Pidgeon, Oxygen-isotope evidence from ancient zircons for liquid water at the Earth's surface 4300 Myr ago, Nature 409 (2001) 178-181.

[19] I.H. Campbell, Implications of $\mathrm{Nb} / \mathrm{U}, \mathrm{Th} / \mathrm{U}$ and $\mathrm{Sm} / \mathrm{Nd}$ in plume magmas for the relationship between continental and oceanic crust formation and the development of the depleted mantle, Geochim. Cosmochim. Acta 66 (2002) 1651-1661.

[20] T. Lay, Q. Williams, E.J. Garnero, The core-mantle boundary layer and deep Earth dynamics, Nature 392 (1998) 461-468.

[21] R.D. van der Hilst, K. Kárason, Compositional heterogeneity in the bottom $1000 \mathrm{~km}$ of Earth's mantle: towards a hybrid convection model, Science 283 (1999) 1885-1888.

[22] A.W. Hofmann, W.M. White, Mantle plumes from ancient oceanic crust, Earth Planet. Sci. Lett. 57 (1982) 421-436.

[23] I. Tolstikhin, A.W. Hofmann, Early crust on top of the Earth's core, Phys. Earth Planet. Inter. 148 (2004) 109-130.

[24] U.R. Christensen, A.W. Hofmann, Segregation of subducted oceanic crust in the convecting mantle, J. Geophys. Res. 99 (1994) 19867-819884.

[25] G.F. Davies, Stirring geochemistry in mantle convection models with stiff plates and slabs, Geochim. Cosmochim. Acta 66 (2002) $3125-3142$.

[26] J.X. Mitrovica, Haskell [1935] revisited, J. Geophys. Res. 101 (1996) 555-569.

[27] M. Ogawa, Chemical stratification in a two-dimensional convecting mantle with magmatism and moving plates, J. Geophys. Res. 108 (2003) 2561, doi:10.1029/2002JB002205.

[28] G.F. Davies, Cooling the core and mantle by plume and plate flows, Geophys. J. Int. 115 (1993) 132-146.

[29] A. Yasuda, T. Fujii, K. Kurita, Melting phase relations of an anhydrous mid-ocean ridge basalt from 3 to $20 \mathrm{GPa}$ : implications for the behavior of subducted oceanic crust in the mantle J. Geophys. Res. 99 (1994) 9401-9414.

[30] D.P. McKenzie, M.J. Bickle, The volume and composition of melt generated by extension of the lithosphere, J. Petrol. 29 (1988) 625-679.

[31] T. Irifune, A.E. Ringwood, Phase transformations in subducted oceanic crust and buoyancy relationships at depths of 600 $800 \mathrm{~km}$ in the mantle, Earth Planet. Sci. Lett. 117 (1993) 101-110.

[32] K. Hirose, Y. Fei, Y. Ma, H.-K. Mao, The fate of subducted basaltic crust in the earth's lower mantle, Nature 397 (1999) $53-56$.

[33] S.R. Hart, E.H. Hauri, L.A. Oschmann, J.A. Whitehead, Mantle plumes and entrainment: isotopic evidence, Science 256 (1992) $517-520$. 